\title{
Cerebral palsy: social class differences in prevalence in relation to birthweight and severity of disability
}

\author{
V M Dowding, C Barry
}

\begin{abstract}
Study objective-The aim of the study was to examine the possible influence of social class on the prevalence of cerebral palsy.

Design-The study was a retrospective population based survey of all cases of cerebral palsy.

Setting-The study involved all cases of cerebral palsy born to residents in the Eastern Health Board area of the Republic of Ireland between 1976 and 1981 inclusive.

Patients-There were 289 cases of cerebral palsy during the study period. Thirty one were excluded because they were attributable to postneonatal brain damage, leaving $\mathbf{2 5 8}$ children for analysis. Cases with uncertain diagnosis were excluded.
\end{abstract}

Main results-There was a clear social class gradient in the overall prevalence of cerebral palsy, also evident in the individual syndromes of hemiplegia and diplegia. No such gradient was detected in the other syndromes, either singly or in combination. Among cases of low birthweight $(\leqslant 2500 \mathrm{~g}$ ), the prevalence was the same across the social class range after allowing for the increased low birthweight rate in the lower social class categories. Among normal birthweight cases there was a strong positive association with decreasing social class. Intrauterine growth retardation seemed to be a factor in cerebral palsy in all social class groups. Prevalence of cerebral palsy severe enough to prevent walking by the fourth birthday, but not of cases ambulant by this age, increased with socioeconomic disadvantage.

Conclusions-The clear social class gradients in hemiplegia and diplegia suggest that environmental factors play an important role in the aetiology of these syndromes, but there was no evidence of a contribution from this type of factor in the remaining types of cerebral palsy.

Community Health,

University of Dublin, Trinity College,

Dublin 2, Republic of

Ireland

V M Dowding

Central Remedial

Clinic, Penny Ansley

Building, Vernon

Avenue, Clontarf,

Dublin 3, Republic of

Ireland

C Barry

Correspondence to:

Dr Dowding

Accepted for publication November 1989

Tor low birthweight and perinat mortality, both of which show steep linear social class gradients in the Irish population (unpublished data, and ${ }^{1}$ ), as in many others. In contrast, the relation between social class and cerebral palsy has been largely neglected. There has been no study which has provided data on the prevalence of cerebral palsy by social class in a geographically defined population of births. It is acknowledged that cerebral palsy includes a agreement on the subdivision of the cerebral palsies is still incomplete.

The analysis of health statistics by social class has many critics who understandably dislike the unscientific political overtones of the term. The method is admittedly crude and a measure of level of education coupled with improved recording of occupational histories would be preferable for health studies, but routine questioning as to education might prove even less acceptable than occupation, without offering the added bonus of occupational analysis. To abandon analysis by social class as suggested by some $e^{2}$ will not help to reduce the differentials in health which still clearly exist. The presence or absence of a social class gradient, its steepness, and the incidence in the most favoured group are useful epidemiological descriptors of any disease and provide one of the basic clues to aetiology and prevention.

The present study comprises an analysis of the relation of cerebral palsy, subdivided into the main syndromes, to social class and birthweight in an unselected series of cases of cerebral palsy among births to residents of a geographically defined area in the Republic of Ireland in 19761981. Findings in relation to prevalence and birthweight have been presented elsewhere. ${ }^{3}$ They showed that prevalence of cerebral palsy, excluding cases caused by postneonatal insult, increased from 1.56 to $1.89 / 1000$ livebirths between the two study periods 1976/78 and $1979 / 81$. Increases occurred only among infants with birthweight $\leqslant 2000 \mathrm{~g}$ and $>3000 \mathrm{~g}$. Among very low birthweight infants $(\leqslant 1500 \mathrm{~g}$ ) the statistically significant increase in prevalence was caused by increase in severe cases. ${ }^{4}$ There was a consistent and significant deficit in weight for gestational age throughout the gestational age range, suggesting that prenatal factors were commonly involved in the aetiology of cerebral palsy. The mainly environmental factors associated with social class differences are likely to have their greatest influence on the occurrence of cerebral palsy in the prenatal period rather than in the neonatal period. Analysis of the relationship with social class therefore seems a logical second step in a systematic search for insights into the aetiology of cerebral palsy. number of different disease entities, although

\section{Methods}

The data base consisted of all 289 cases of cerebral palsy born between 1976 and 1981 inclusive to residents of the Eastern Health Board's area of the Republic of Ireland. For the purposes of this analysis the 31 cases attributable to a recognised postneonatal insult were excluded. Cases with 
definite clinical manifestations of spasticity or dyskinesia in the form of athetosis, dystonia (almost invariably with spasticity), or ataxia were included. Cases where these signs were absent, or there was doubt about their presence, were excluded. The problem of the cut off point at the mild end of the severity range has been discussed. ${ }^{3}$ The sources of cases, ascertainment procedures, and a listing of inclusions and exclusions have already been described. ${ }^{3}$ Classification into type of cerebral palsy follows that of Hagberg. ${ }^{5}$

The father's occupation was coded for a regular one in three sample of the notifications of all 150189 births to residents of the study area between 1976 and 1981. Notifications provided a one or two word description of the husband's occupation. Where a mother was not married, no occupation was recorded. Occupations were coded for this study according to the British Registrar General's (1978) listing of social classes into the following categories: $1 / 2=$ higher and lower professional; $3 \mathrm{~N}=$ other non-manual; $3 \mathrm{M}=$ skilled manual; $4 / 5=$ semi- and unskilled manual. In order to provide valid prevalence rates the same classification of occupation was used for cases as for the source population. Unmarried mothers were placed in a separate group. Military, unemployed and unknown were placed together in a final group. This last heterogeneous group of largely unknown composition was excluded from the analysis of social class patterns, leaving 237 cases among social classes $\mathrm{I}$ to $\mathrm{V}$ and unmarried mothers. These social class groups were directly comparable with those used in a previous analysis of the relation between birthweight, social class, and birth order among 20698 singleton births to Dublin residents in 1978/9, which showed a clear social class gradient in low birthweight. Infants of unmarried mothers, even within birth order categories, had a higher incidence of low birthweight $(\leqslant 2500 \mathrm{~g}){ }^{1}$ and higher perinatal mortality rates (unpublished data) than all other groups. To allow comparison with the commonly studied indicators of adverse pregnancy outcome, this group of mothers has been included as the last of the "social class" groups. The birthweight distribution for singleton infants by social class has been taken from this large population of births in the middle of the present study period to provide a standard for the calculation of the cerebral palsy rates expected on the basis of the birthweight distribution in the several social classes.

A clear social class gradient in the incidence of low birthweight $(\leqslant 2500 \mathrm{~g})$ has been demonstrated in the Dublin population, 1978/9. ${ }^{1}$ This alone might be expected to give rise to a gradient in prevalence of cerebral palsy as a result of the well known association of cerebral palsy with low birthweight, clearly confirmed in the present study. ${ }^{3}$ In order to examine the effect of birthweight distribution alone, the expected population prevalence of low birthweight cases was calculated for each social class, except the reference class $1 / 2$, as follows: (1) the prevalence of low birthweight cases of cerebral palsy among all births in social classes $1 / 2$ was taken as the standard prevalence; (2) the expected prevalence of low birthweight cases of cerebral palsy in each of the other social classes was obtained by multiplying the standard prevalence by the ratio of the proportion of low birthweight births in the appropriate social class to the proportion in social classes $1 / 2$. The calculations were repeated to provide the expected population prevalence of normal birthweight ( $>2500 \mathrm{~g}$ ) cerebral palsy.

All cases were followed from the time of ascertainment to at least age five years and all available pre-existing records were also examined. This provided an invaluable historical picture of the development of each child including information as to whether he or she had achieved independent walking by the fourth birthday. This gave a crude but robust indicator of the severity of a motor impairment. Very severe cases who died before four years were classified as non-ambulant. Non-ambulant cases will be referred to as severe.

\section{STATISTICAL METHODS}

Spearman's rank correlation coefficient $\left(r_{s}\right)$ was computed to test for the presence of a significant trend in prevalence with social class. Significance of the difference between two prevalences was tested with the following methods: $\chi^{2}$ for $2 \times 2$ contingency tables with $1 \mathrm{df}^{6}$ the Student $t$ test for the difference between two proportions; ${ }^{7}$ and comparison of the $95 \%$ confidence limits for the difference between two proportions with the observed difference. ${ }^{8}$ Results have been recorded as significant if probability of a similar result occurring by chance was $<0.05$ except where multiple testing was applied (between pairs of social classes in relation to the same variable), for which the significance requirement was raised to $\mathrm{p}<0.025$. On the one occasion where the three tests did not agree the difference was treated as non-significant.

\section{Results}

The number of cases and of births in each of the several social classes is given in table I. The prevalence of cerebral palsy increased with descending social class status (fig 1). Spearman's correlation analysis showed that this upward trend was significant $\left(r_{s}=1.0, p<0.01\right)$. Prevalence was 1.23 in social classes $1 / 2,2.02$ in social classes $4 / 5$ and $2 \cdot 45 / 1000$ births in the unmarried mothers. Prevalence was significantly lower in social classes $1 / 2$ than in social classes $4 / 5$ $(\mathrm{p}<0.025)$ and the unmarried $(\mathrm{p}<0.01)$ (difference between social classes $1 / 2$ and $3 \mathrm{M}$ : $\mathrm{p}<0.05)$. The same rising trend in prevalence with increasing socioeconomic disadvantage was clear both in $1976 / 8\left(r_{s}=0.8, p<0.05\right)$ and in $1979 / 81\left(r_{s}=1.0, p<0.01\right)$. There was no change in prevalence among social classes $1 / 2$ but all of

Table I Number of births and prevalence per 1000 births of cerebral palsy (CP) by social class

\begin{tabular}{lll}
\hline Social class & Births & $\begin{array}{l}\text { Prevalence of } C P \\
\text { (number of cases) }\end{array}$ \\
\hline $1 / 2$ & 27685 & $1.23(34)$ \\
$3 \mathrm{~N}$ & 22831 & $1.40(32)$ \\
$3 \mathrm{M}$ & 44784 & $1.88(84)$ \\
$4 / 5$ & 31176 & $2.02(63)$ \\
Unmarried & 9785 & $2.45(24)$ \\
Others & 13928 & $1.51(21)$ \\
Total & 150189 & $1.72(258)$
\end{tabular}


Figure 1 Prevalence (per 1000 births) of cerebral palsy by social class among births 1976-78 and 1979-81

Figure 2 Prevalence (per 1000 births) of diplegia ( ), hemiplegia ( $\square$ ) and other types of cerebral palsy (O) by social class

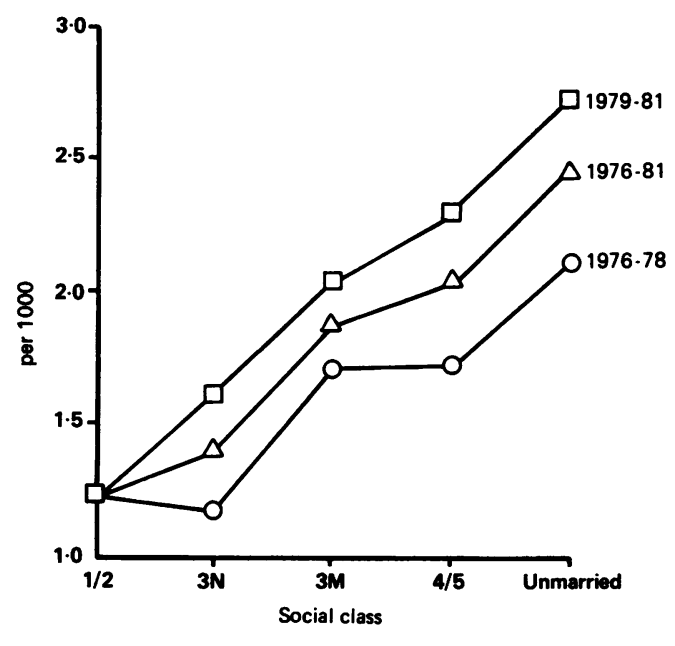

the other four groups suffered increases, and the social class gradient became steeper. None of the individual social class increases reached the required level of statistical significance.

The prevalence of both hemiplegia and diplegia (combined spastic and ataxic types) showed significant upward trends with descending social class (fig 2), Spearman's coefficients with social class $(n=5)$ for hemiplegia and diplegia being 0.9 $(p<0.01)$, and $1.0(p<0.01)$ respectively. Prevalence of hemiplegia ( 62 cases) was 0.32 in the non-manual groups, 0.53 in the manual, and

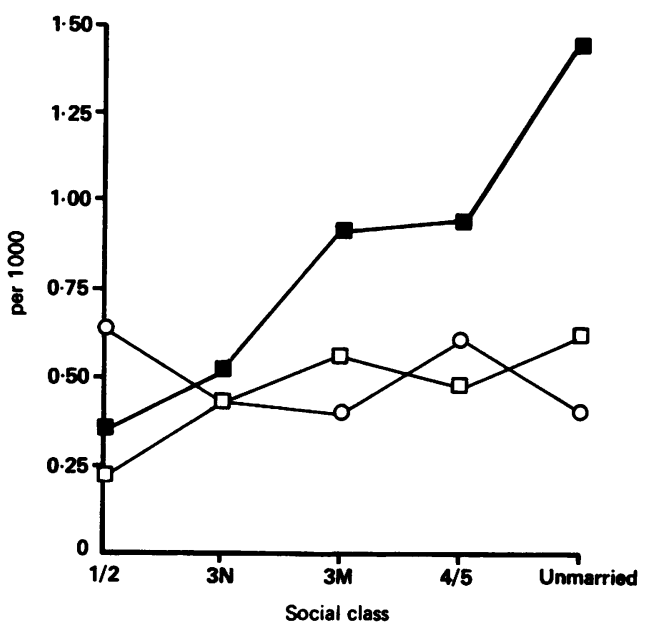

$0.61 / 1000$ births in the unmarried, and equivalent rates for diplegia (106 cases) were $0.44,0.92$ and $1.43 / 1000$ births. The prevalence of hemiplegia was significantly lower in social classes $1 / 2$ than in $3 M$ ( $p<0.025$ ) (difference between social classes $1 / 2$ and unmarried: $p<0.05)$. Prevalence of diplegia was significantly lower in social classes $1 / 2$ than in $3 \mathrm{M}, 4 / 5$ and the unmarried, and in $3 \mathrm{~N}$ than in the unmarried, all four differences being highly significant $(p<0.005)$. There was no evidence of any social class gradient in any of the other types of cerebral palsy, either separately or taken together as a group, and no significant difference between any pair of social classes.

The social class gradient in prevalence was evident in severe cerebral palsy (fig 3). Prevalence was significantly higher in the unmarried than in each of social classes $1 / 2,3 \mathrm{~N}$ and $3 \mathrm{M}$ (all p $<0.005$ ) (difference between social classes
1/2) and 4/5: $p<0.05$ ). There was no evidence of a consistent trend in prevalence of cases who were able to walk by their fourth birthday. The only significant difference was between social classes $1 / 2$ and $3 M(p<0.025)$.

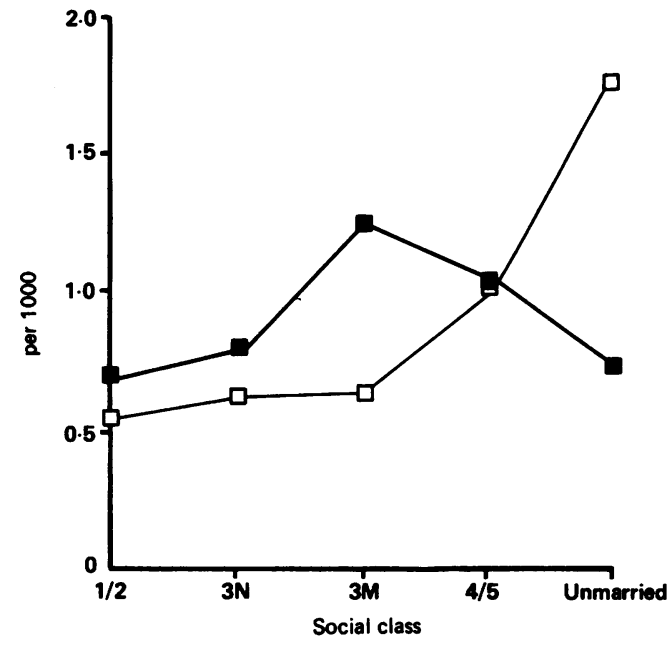

Figure 3 Prevalence (per 1000 births) of non-ambulant ( $\square$ ) and ambulant cases ( $\square$ ) of cerebral palsy by social class

Seventeen cases who were twins were excluded from analysis of prevalence in relation to birthweight, leaving 220 singleton cases of cerebral palsy. The weight-specific prevalence of cerebral palsy in singleton low birthweight infants showed no consistent pattern with social class and no two social classes differed significantly (table II). In contrast, prevalence among normal birthweight children ( $>2500 \mathrm{~g}$ ) increased with decreasing social class (Spearman's $r_{s}=1 \cdot 0$, $\mathrm{p}<0.01)$.

Table II Birthweight specific prevalence of cerebral palsy (/1000 births) among singleton infants $\leqslant 2500 \mathrm{~g}$ and $>2500 \mathrm{~g}^{a}$

\begin{tabular}{lcl}
\hline Social class & $\leqslant 2500 \mathrm{~g}$ & $>2500 \mathrm{~g}$ \\
\hline $1 / 2$ & 9.4 & 0.89 \\
$3 \mathrm{~N}$ & 14.8 & 0.91 \\
$3 \mathrm{M}$ & 8.1 & 1.37 \\
$4 / 5$ & 9.8 & 1.48 \\
Unmarried & 12.6 & 1.56 \\
\hline See text for method of calculation &
\end{tabular}

The observed pattern of population prevalence of low birthweight cases of cerebral palsy was similar to the predicted pattern (fig 4). There was therefore no evidence of a social class gradient in low birthweight cerebral palsy apart from that caused by the different incidences of low birthweight births in the social classes. In contrast, the observed prevalence of normal birthweight cerebral palsy differed from the predicted pattern. Rates were significantly higher than predicted on the basis of birthweight distribution alone in social classes $3 \mathrm{M}$ and $4 / 5$. The highest observed prevalence was among the unmarried mothers but small numbers precluded statistical significance. The observed overall social class gradient therefore resulted mainly from the gradient in the prevalence of cerebral palsy in the large majority of the population of babies who weighed more than $2500 \mathrm{~g}$ at birth. 


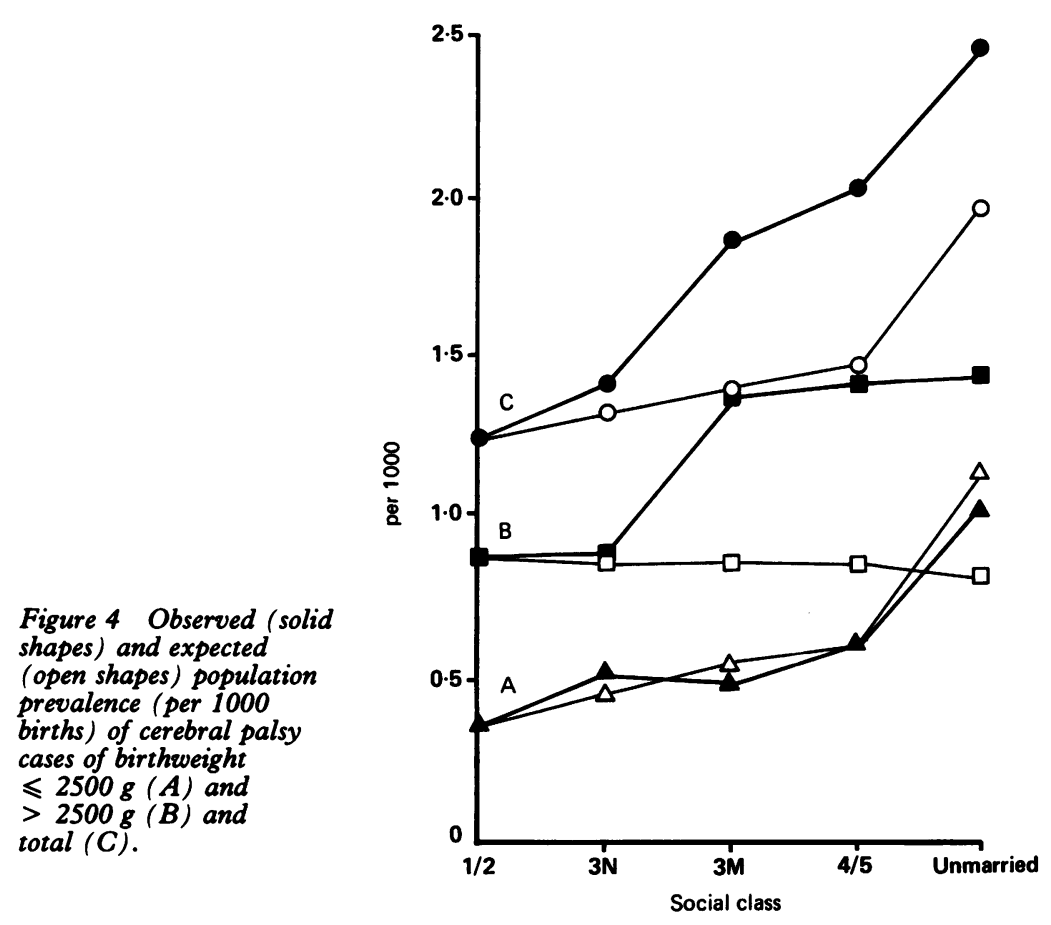

If the prevalence in social classes $1 / 2$ is accepted as the lowest that can at present be achieved, 69.6 of the 237 cases are attributable to the action of social class related factors, a population attributable risk for social class of $29 \%$. The $95 \%$ confidence interval of the difference between the observed prevalence and the prevalence expected if all social classes had the same prevalence as social class I/II was $\pm 29 \%$. The population attributable risks for diplegia and hemiplegia were $54 \%(95 \% \mathrm{CI}, 23 \%)$ and $52(30) \%$ respectively.

In each of the non-manual, manual and unmarried groups, $37 \%-40 \%$ of singleton cases were in the lowest 25th centile of weight for gestational age, birth order and sex of the source population. There was therefore a deficit in weight for dates in all social class groups but no major differences between them.

\section{Discussion}

UNMARRIED MOTHERS

During the study period unmarried pregnancy was severely frowned upon and one quarter of unmarried mothers giving birth in Dublin hospitals in the year to March $1979,80 \%$ of whom were under 25 years old, spent the last months of their pregnancies in homes for unmarried mothers or with families who had taken them in after they had to leave their own homes (unpublished observations). To choose to have a baby without marrying was rare, and unmarried mothers were a disadvantaged group, suffering educational, social and economic hardship greater than any others. Dissemination of information about contraception and abortion was illegal so that among the sexually active, avoidance of unwanted pregnancy and termination abroad were probably more or less restricted to the most educated groups, thus increasing the overall level of disadvantage among births to the unmarried. The unmarried group suffered a higher incidence of low birth weight ${ }^{1}$ and of perinatal mortality (unpublished observations) than any of the other social class groups and this pattern was repeated in the prevalence of hemiplegia and diplegia.

PREVALENCE OF CEREBRAL PALSY

There was a significant rising trend in the overall prevalence of cerebral palsy with decreasing social class status. Hemiplegia and diplegia both showed significant gradients, most marked in diplegia. No other type of cerebral palsy, or the remaining types taken together as a single group, showed any trend in prevalence with social class. The results suggest that some social class related factor, or group of factors, influenced the occurrence of hemiplegia and diplegia but had little or no effect on the other types. Such an influence may be superimposed on a basic level attributable to other factors. Search for environmental factors may yield valuable information for hemiplegia and diplegia but prove fruitless for the remaining one third of cases of cerebral palsy, the mixed athetoid/spastic types and the pure athetoid and pure ataxic types.

There was a strong social class gradient in prevalence of severe but not of mild (ambulatory) cases of cerebral palsy. This difference was evident and very similar in both low birthweight and normal birthweight cases. There may be some tendency toward underutilisation of paediatric health services and a reluctance to follow up initial referrals for assessment among the lowest socioeconomic groups. This would reduce the ascertainment of the mildest cases of cerebral palsy in these groups but it is unlikely that such an effect was large enough to account for the observed difference.

There was a real social class gradient in prevalence of cerebral palsy cases of normal birthweight $(>2500 \mathrm{~g})$. There was no gradient in low birthweight cases of cerebral palsy beyond that which was expected from the proportion of low birthweight births in each of the social classes. It is, however, possible that the factors which cause premature delivery, including some related to social class, may also cause growth failure and predispose to cerebral palsy.

OTHER STUDIES

The available information about the relationship between social class and cerebral palsy is limited and conflicting, and there has been a conspicuous lack of data on social class differences in prevalence. Many observations have been limited by small numbers. McDonald ${ }^{9}$ collected 1081 survivors $<1800 \mathrm{~g}$ birthweight including 57 with spastic diplegias (using a wider definition than in the present paper). She found no significant difference in social class distribution between all births and births $<1800 \mathrm{~g}$, but a suggestion that, among the low birthweight sample, the manual groups had more cases of diplegia than expected (19 instead of 11.5). Atkinson and Stanley ${ }^{10}$ were only able to obtain the father's occupation for $70 \%$ of 198 cases of spastic diplegia born in 1956-1975, and for the population of births from 1968-75. Reliable population birthweights were available for 1968-75. They considered that the only significant difference was an excess of labourers among the fathers of the low birthweight cases, but pointed out that the coding 
of father's occupation in Western Australia made it difficult to discriminate clearly between social class categories. Dunn and his colleagues ${ }^{11}$ followed 335 children with birthweights $<2041 \mathrm{~g}$ and found that the social class distribution among the 27 cases of cerebral palsy did not differ significantly from the rest of the low birthweight group. This last finding accords with the present results, showing no social class gradient in low birthweight cerebral palsy beyond that attributable to the gradient in incidence of low birthweight itself.

Drillien and colleagues, ${ }^{12}$ using a clinic based sample of cases of diplegia, noted a significantly higher percentage of social classes 1/2 among diplegics of birthweight $>2.4 \mathrm{~kg}$, and of social classes $4 / 5$ in those $<2.0 \mathrm{~kg}$ compared with hospital controls of similar weight. The controls were not fully comparable and those of low birthweight had a significant deficit of social class $4 / 5$ compared with the general population of Scottish births. The almost universal use of percentages, often with small numbers of cases, in the few analyses of social class and cerebral palsy which are available, is unhelpful. Prevalences must be obtained for a proper assessment. Taylor and colleagues ${ }^{13}$ found no significant differences from the source population in the proportional distribution among the social classes of 12 cases, the numbers being too small for this purpose. Lagergren's Swedish data ${ }^{14}$ on 182 cases born in 1960-1972 showed a higher percentage of cases in the highest of three social groups than in the Swedish population in general. The present results do not confirm this observation but are more correctly based on the population of births only.

No concensus has emerged from earlier studies on the relationship of cerebral palsy and social class, but there has been an absence of adequate studies designed specifically to answer this question. The present results have shown a definite social class gradient, exhibiting increasing prevalence of hemiplegia and diplegia, but not of the other types of cerebral palsy, with increasing socioeconomic disadvantage in Ireland. The social class effect seemed to be concentrated among normal birthweight children and to affect the severe cases more than the milder cases.

We wish to record our appreciation of financial support from the Scientific and Research Committee of the Central Remedial Clinic, Dublin, and of the professional advice which has been freely available throughout the study from the paediatric and physiotherapy teams at the clinic, as well as from many physicians and physiotherapists in the Eastern Health Board area.

1 Dowding VM. New assessment of the effects of birth order and socioeconomic status on birthweight. $\mathrm{Br} M e d \mathcal{F} 1981$; 282: $683-6$.

2 Jones IG. Social class analysis-an embarrassment to epidemiology. Community Med 1982; 6: 37-46.

3 Dowding VM, Barry C. Cerebral palsy: changing patterns of birthweight and gestational age (1976-1981). Ir Med $\mathcal{F}$ 1988; 81: 25-9.

4 Dowding VM. Conference report: Epidemiology of cerebral palsy, Cambridge, UK, April 1989. Ir Med ₹ 1989; 82: 77-8.

5 Hagberg B, Hagberg G, Olow I. The changing panorama of cerebral palsy in Sweden 1954-1970. I. Analysis of the general changes. Acta Paediatr Scand 1975; 64: 187-92.

6 Siegel S. Nonparametric statistics for the behavioural sciences. New York: McGraw-Hill Book Co, 1956: 104-11.

7 Daniel WW. Biostatistics: a foundation for the health sciences, 3rd ed. New York: J. Wiley \& Sons, 1983: 130-1.

8 Snedecor WS, Cochran WG. Statistical methods, 7th Ed. Iowa: Iowa State University Press, 1980.

9 McDonald $\mathrm{AD}$. Cerebral palsy in children of very low birthweight. Arch Dis Child 1963; 38: 579-88.

10 Atkinson S, Stanley FJ. Spastic diplegia among children of low and normal birthweight. Devel Med Child Neurol 1983; 25: 693-708.

11 Dunn HG, Robertson A-M, Crichton JU. Clinical outcome: neurological sequelae and their evolution. In: Dunn HG, ed. Sequelae of low birthweight: the Vancouver study. ed. Sequelae of low birthweight: the Vancouver study. Oxford: Blackwell Scientific Publicat

12 Drillien CM, Ingram TTS, Russell EM. Comparative aetiological studies of congenital diplegia in Scotland. Arch Dis Child 1962; 37: 282-8.

13 Taylor DJ, Davidson J, Howie PW, Davidson D, Drillien CM. Do pregnancy complications contribute to neurodevelopmental disability? Lancet 1985; i: 713-6.

14 Lagergren J. Children with motor handicapsepidemiological, medical and socio-paediatric aspects of motor-handicapped children in a Swedish county. Acta Paediatr Scand 1981: Suppl 289. 